\title{
Understanding Public Environmental Awareness and Attitudes toward Circular Economy Transition in Saudi Arabia
}

\author{
Abdulaziz I. Almulhim 1,*(D) and Ismaila Rimi Abubakar ${ }^{2}$ (D) \\ 1 Department of Urban and Regional Planning, College of Architecture and Planning, Imam Abdulrahman Bin \\ Faisal University, Dammam 31451, Saudi Arabia \\ 2 College of Architecture and Planning, Imam Abdulrahman Bin Faisal University, \\ Dammam 31451, Saudi Arabia; irabubakar@iau.edu.sa \\ * Correspondence: aialmulhim@iau.edu.sa
}

Citation: Almulhim, A.I.; Abubakar, I.R. Understanding Public

Environmental Awareness and

Attitudes toward Circular Economy Transition in Saudi Arabia.

Sustainability 2021, 13, 10157. https:/ / doi.org/10.3390/su131810157

Academic Editors: Elena Cristina Rada and Lucian-Ionel Cioca

Received: 13 July 2021

Accepted: 8 September 2021

Published: 10 September 2021

Publisher's Note: MDPI stays neutral with regard to jurisdictional claims in published maps and institutional affiliations.

Copyright: (c) 2021 by the authors. Licensee MDPI, Basel, Switzerland. This article is an open access article distributed under the terms and conditions of the Creative Commons Attribution (CC BY) license (https:/ / creativecommons.org/licenses/by/ $4.0 /)$.

\begin{abstract}
Circular economy (CE) has been globally acknowledged as a national sustainable development (SD) strategy to confront resource shortages and environmental contamination challenges. Although public behaviors and lifestyles play an essential role in achieving sustainability, in developing countries, few studies explored the role of public awareness, attitudes, and lifestyles on CE transition. Thus, it is necessary to elicit public opinion to understand their awareness and attitude regarding CE strategy to determine obstacles to CE implementation and approaches of overcoming them. This study thus focuses on understanding public awareness and attitudes to CE transition in Saudi Arabia. Data were collected through a questionnaire survey distributed to 402 residents of the Dammam Metropolitan Area. The results indicated that the respondents had little understanding of the CE concept due to limited awareness of the topic. However, they held an optimistic attitude towards trash separation and classified their trash as "can be sold", "reused", and "exchanged for a new one". Furthermore, the respondents' level of awareness regarding the CE transition is positively related to their level of education. In contrast, the inclination towards resource conservation and pro-environmental behavior positively correlates to the age demographic. This paper thus contributes to the empirical literature on CE transition by exploring the public awareness and attitudes towards its implementation in Saudi Arabia.
\end{abstract}

Keywords: circular economy; policy implementation; public awareness; attitudes; resource efficiency; Saudi Arabia; sustainable development; urban sustainability

\section{Introduction}

A circular economy $(\mathrm{CE})$ is a framework that promotes maximum efficiency in using finite resources, where value is given to each part of the lifecycle of materials, commodities are devised to offer lasting values, emissions and leakages are curtailed through "slowing, closing, or narrowing material and energy loops", and waste is viewed as a resource and input for further manufacturing [1]. The concept of CE can help address the tremendous ecological externalities related to the linear "take, make, trash" manufacturing framework [2]. Besides waste management, CE is also implemented in materials efficiency, product design, product recycling, electro-mobility, and promoting low-carbon city [3-6]. It is a worldwide strategy where the conventional linear economic framework is shifted to a closed-loop framework by considering the connection between materials use and waste residuals $[7,8]$. The growing awareness among policymakers and the public regarding resource shortages and environmental sustainability is a major driving force propelling the CE transition worldwide [9-11].

In Saudi Arabia, industrial growth, rapid urbanization ( $83 \%$ of the population living in cities as of 2010), and a high-consumption lifestyle has led to many environmental issues, including the degradation of ecosystems, depletion of natural resources, and extensive environmental pollution [12]. To address these issues, the government aims to transform its 
economy to a CE as stipulated in the Saudi Vision 2030, which led to establishing the Saudi Investment and Recycling Company (SIRC) to oversee the transition [13]. Three reasons can be provided for the transition to $\mathrm{CE}$ in the country. First, the recent government policy change seeks to build an environmentally friendly society that focuses on saving nature's irreplaceable resources. The second reason is the drastic rise in raw materials costs spurred by economic growth. Lastly, severe environmental problems result from rapid urbanization, industrialization, and a high-consumption lifestyle [14]. Thus, decreasing energy and resources consumption, industrial pollution, and sustainable waste management is the primary focus of the country's transition to CE.

The Vision 2030's target of creating a prosperous economy supports the country's CE transition through several initiatives [15-17]. For example, by 2030, it aims to meet $50 \%$ of its energy requirements from renewable resources. Additionally, through the Saudi Green Initiative 2021, tree planting and clean energy utilization are expected to contribute to carbon sequestration and curbing carbon dioxide emissions significantly. Similarly, CE is reinforced by the circular carbon economy (CCE) that underpins the 4 Rs of reuse, reduce, recycle, and remove deleterious atmospheric products. Other policies that can enhance the $\mathrm{CE}$ in the country include economic incentives, legislative instruments, sectoral projects, industrial restructuring, research and development, and staff training [18-20].

The Saudi government is thus implementing a CE strategy based on ideas that worked in some developed countries, especially the recycling feat of Germany, Japan, and China. However, the concept of CE has not been fully understood by the Saudi public. The issues of public awareness, attitudes, and participation are not included in the CE transition programs, as highlighted above. Hence, the present study aims to explore the level of public awareness of CE strategies and the extent to which their attitudes can support CE transition in Saudi Arabia. According to van Langen et al. [21] (p. 8), "citizens with their consumption choices and actions influence directly and indirectly the transition to CE". As "behaviors and lifestyles play a vital role in achieving sustainable development", it is "necessary to conduct questionnaire surveys to understand public awareness and performance, as well as related progress, so that the barriers on CE implementation can be identified" [8] (p. 2177). Several other works of literature emphasize the importance of not only the role of government agencies and private companies in CE transition but also the awareness, attitudes, and choices of citizens as vital CE stakeholders [22-25].

There is a dearth of studies on the role of consumer behavior and lifestyle on CE transition in developing countries, as only a few countries have taken preliminary actions towards CE transition [7]. In Urumqi city (western China), Guo et al. [8] investigated public awareness on CE and their attitudes toward reusing water and shopping bags and using energy-saving lamps at home. Marios et al. [24] explored public awareness of $\mathrm{CE}$ and the factors influencing its promotion in Thessaloniki, Greece. The study found limited awareness of $\mathrm{CE}$, although the residents hold a positive attitude toward the model. These studies, however, have not investigated CE strategies of purchasing green products or repairing electronics. Kuah and Wang [22] found few consumers buying recycled electronics in East and Southeast Asia. Khan and Haleem [26] reviewed the literature on CE practices in emerging economies. They concluded that while literature is scarce on this subject, transforming economies from linear to circular requires practices that include awareness among consumer and supply chain partners, sound legislation, and policies, developing the circular culture among all stakeholders, and designing products for circularity.

Therefore, the present study asks an important research question: to what extent is the public aware of $\mathrm{CE}$ and willing to be involved in behaviors capable of supporting the nascent drive for CE transition in Saudi Arabia? To the authors' knowledge, this study is the first of its kind in the country. This study can provide insight into the likelihood of green consumption, attitudes towards sorting and recycling trash, and energy and water conservation among the public. The study can also help in implementing public awareness and involvement strategies as social aspects of CE. It also improves our knowledge of the 
emerging body of empirical literature on public awareness of and attitudes on CE towards enhancing socioeconomic and environmental development in Saudi Arabia and other emerging economies. Globally, the implementation of CE is still at an early developmental stage [7]. The next section of the paper explains the study's theoretical framework, followed by the methods in section three. The fourth section presents and discusses the study findings and section five concludes with the study's implications, limitations, and future research direction.

\section{Theoretical Framework}

The CE is "part of a resource-efficient, sustainable way of life and management that encompasses not only traditional waste management but all phases of material and product life cycles" and respecting planetary boundaries [5] (p. 8). It is part of environmental sustainability strategies that reinforce realizing the UN's Agenda 2030 for SD by helping "to protect natural resources and the climate, as well as the environment and human health" [27], and secure raw material supplies [28]. It is "meant to reduce negative impacts along the life cycle of materials and products by managing materials in same or higher value cycles so that primary materials can be substituted by secondary material of suitable quality, thus economizing on primary material" [4] (p. 4).

The literature on CE can be classified into two categories: theoretical literature and $\mathrm{CE}$ analysis in practice. The theoretical literature on the $\mathrm{CE}$ is more focused on ecological economics, which postulates that the economic system is a sub-component of the earth's ecological system. It supports the fact that the globe has limited environmental and resource capability. Since an unbalanced exchange of materials between the socioeconomic system and the ecosystem during the rapid industrialization of developing and developed countries, a CE acts as a means to an effective problem-solving strategy by reducing the flux and bringing a balance in the flow of materials between the socioeconomic system and the ecosystem [29].

On the other hand, CE analysis in practice promotes waste minimization and focuses on energy efficiency and environmental conservation while simultaneously working on improving country's economic development. These factors create a complete package, inclusive of systemic tools and strategies that can achieve CE goals. The principle of reducing waste, reusing, and recycling energy and materials (3R) is often used to describe the three possible methods of reversing or slowing down pollution in practice [30,31]. Research on this topic began in the 1970s, with researchers from Sweden, Japan, and the UK contributing significantly to the subject over the past decade. Previous research has focused on the green purchase behavior [32,33], change and diversity in patterns of usage, policies calling for a behavior change [34,35], and green consumption [36,37]. The World Population Review [38] expresses the importance of achieving SD through choices, lifestyles, and behavior. It is challenging to examine an individual's behavior and attitude towards SD. Furthermore, it is challenging to introduce purposeful policies in SD.

A CE has its share of advantages and disadvantages. Strict implementation of this set of regulations to conserve energy and resources and reduce pollution requires a long-term SD strategy. Also, because some countries follow a centrally planned economy, the CE has taken a top-down approach. This approach means that public involvement has not been adequately integrated into $C E$ transition at various levels. Instead of maintaining broader views, nearly all CE plans constitute rigid technical solutions such as by-product and company-to-company waste exchange.

Consumer behavior research in the Global South majorly focuses on marketing instead of identifying more sustainable methods to decrease consumption [39]. Although many studies since the early 1990s used surveys to assess people's general environmental knowledge and attitudes towards environmentally sensitive behavior [40], only a handful of studies specifically examined people's attitudes towards CE. Kane [41] reported that although multiple groups from related fields, including non-governmental organizations, 
have also highly invested in the subject, the scope of research is much narrower and often dwells on certain goals that are not directly related to SD or consumption.

The literature indicates that factors influencing public willingness to support $\mathrm{CE}$ include subjective norms and emotions, economic gains, sacrifice for the environment, and ecological awareness level $[42,43]$. The socio-demographic factors that influence consumer perception and attitudes towards SD strategies, such as CE, include education, age, gender, and income/wealth levels. Higher educated populations are expected to be more informed about CE and support sustainable practices more than less educated ones [44,45].

The age of respondents is also theorized to influence awareness and attitudes toward SD initiatives. For example, some studies found that younger people embrace new sustainability initiatives such as treated wastewater reuse, while the elderly are more often conservative [40]. For example, in the Malopolska region of Poland, Smol et al. [25] reported that younger study participants were more familiar with the CE concept and willing to sort waste and buy recycled goods than the elderly. On the contrary, research by Lee and Cho [46] reported that aged persons were more likely to be involved in socially responsible consumption programs such as recycling and reducing the usage of products than younger persons. Similarly, a study in Southern Jordan found that older survey respondents had higher environmental awareness than younger ones [45].

Regarding the influence of gender on awareness and attitudes to CE strategies, previous studies reported mixed results. For example, a survey of users of electronic and electrical appliances in the EU found that, compared with the rest of the population, respondents that are females, older than 50 years, and with medium and high education levels are more willing to purchase appliances with more environmentally friendly end-of-life scenarios [44]. Conversely, some studies showed that males tend to be more aware and supportive of CE strategies [22-24]. These contradictory findings call for more empirical studies on this subject.

In Saudi Arabia, local governments paid extensive attention to major industries, and pollution regulations in down and upriver enterprises but energy input and waste management remained highly ignored. Only the "circular" aspect of CE was prioritized, thus failing to determine its economic, social, and ecological benefits among households and eco-industrial parks [47]. Even though the bottom-up approach to foster the CE has been mentioned, little to no attention has been given to public awareness and involvement.

\section{Materials and Methods}

\subsection{Study Settings}

The present study focused on exploring public awareness of and attitudes toward CE strategies in Dammam Metropolitan Area (DMA), the capital of Saudi Arabia's Eastern Province (Figure 1). The DMA borders the Arabian Gulf and is $380 \mathrm{~km}$ away from Riyadh, the national capital [40]. Dammam has numerous oil reserves, and their discovery in 1938 caused its rapid development from a small fishing settlement to a major seaport. As a result, it is a center for the natural gas and petroleum industries in Saudi Arabia. The metropolis has approximately $800 \mathrm{~km}^{2}$, about 1.279 million residents as of 2021, and a GDP of USD 23,352 per capita in 2020 [48].

The country's CE transition is driven by the National Transformation Program (NTP) that aims to maximize the use of primary and digital infrastructure and stakeholder involvement in a proactive manner to achieve seamless implementation of the initiatives [17]. The NTP initiatives can be summed up in the following themes: transforming healthcare, improving lifestyle and safety, securing the sustainability of vital resources, social empowerment, developing the private sector and non-profit organizations, excellence in governance, labor market accessibility and attractiveness, and expanding tourism and national heritage sectors $[17,49]$. Therefore, determining the NTP's vision can help understand how to achieve excellence with the governmental operations, improve economic enablers, and enhance living standards. 


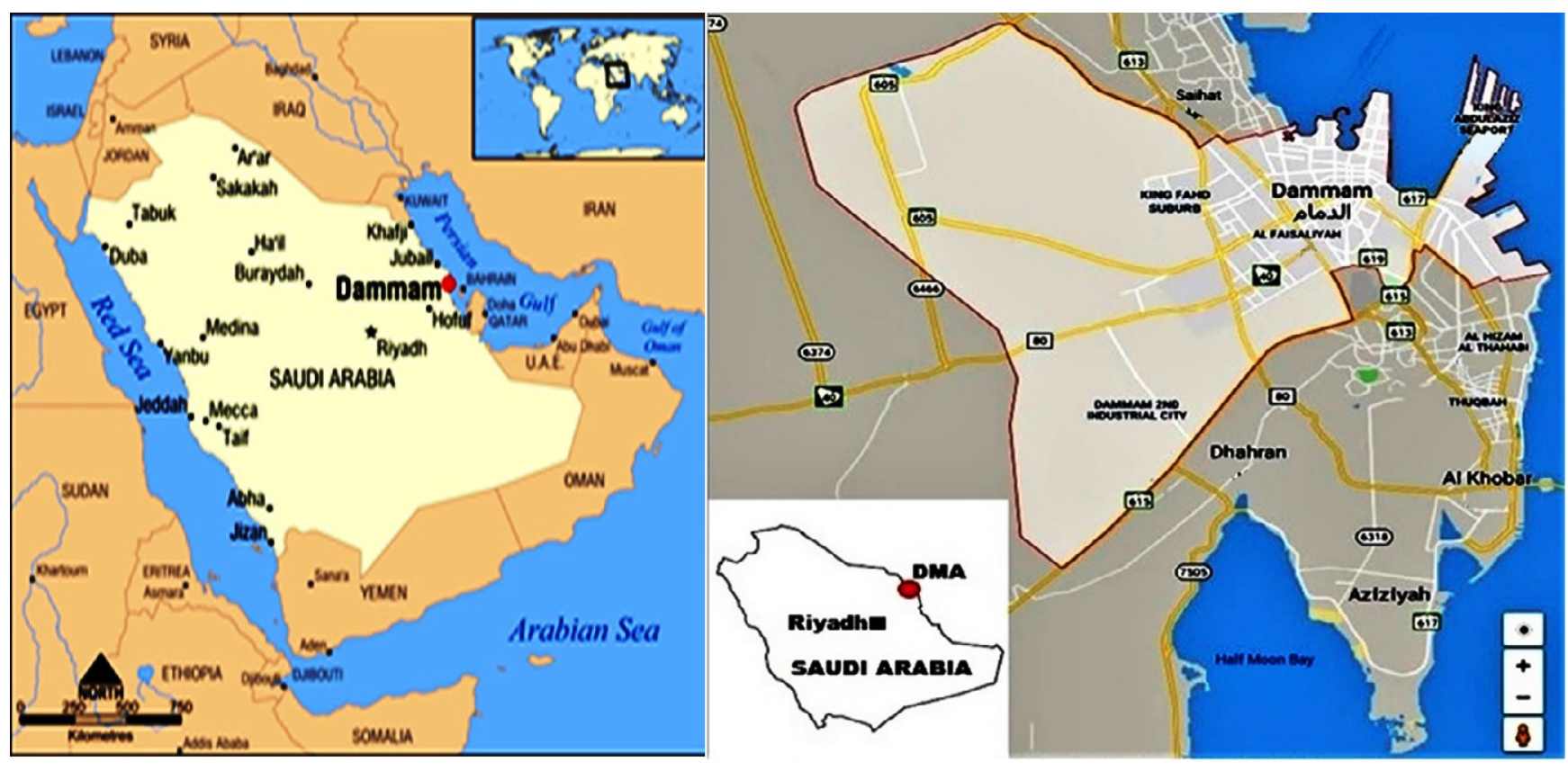

Figure 1. Dammam is a coastal metropolis and the capital of the Eastern Province.

The ongoing transition to CE in Saudi Arabia is related to the six areas of SD covered in the Saudi Vision 2030 [50]:

1. Guarantee sustainable management and accessibility to water and sanitation for all residents;

2. Ensure access to dependable, cost-effective, latest, and sustainable energy;

3. Make residential areas and the cities of Saudi safe, inclusive, resilient, and sustainable;

4. Establish sustainable production patterns and resource usage;

5. Protect, restore, and promote sustainable use of earth's ecosystem, sustainable administration of forests, mitigation of deforestation, reversal of land decomposition, and prevention of loss of biological diversity;

6. Strengthen the modes of executing and revitalizing the global partnership for a sustainable tomorrow.

The vision aims to decrease water consumption per capita from $200 \mathrm{~L}$ by 2020 to 150 L by 2030 [51] and raise municipal use of treated wastewater from 65\% in 2020 to more than $90 \%$ by 2040 [40,52]. Another objective is to increase renewable energy production from 5.3 gigawatts by 2020 to 5.9 gigawatts by 2030 [16] by constructing 508 dams with a total storage capacity of 2.2 billion cubic meters, wind farms, and carbon capture and storage [53]. However, these laudable projects can be more effective with an informed public willing to be involved in behaviors that support CE transition, which the present study explores.

\subsection{Data Collection and Analysis}

Data were collected using a questionnaire composed of eight closed-ended questions with an open-ended question to solicit additional information. The questionnaire consisted of three sections. The first section assessed public attitude towards CE. The questions dwelt on their awareness of the concept of $\mathrm{CE}$, their opinion about trash segregation, the purchase of environmentally friendly (green) goods, and whether they preferred to rent/share a product rather than buying a new one. The second section focused on uncovering public behavior regarding preservation practices in their day-to-day life and their conduct during and after purchasing green products. For example, the questions were about repairing and maintaining electronics and machines, electricity and water conservation, and reusing or discarding commodities and their packages after use. The third section inquired about 
respondents' demographic details, including gender, age, marital status, income, and education level (Table 1). The review of relevant studies informed variable selection and questionnaire design $[8,11,21,24]$.

Table 1. Demographic composition of the study participants $(n=402)$.

\begin{tabular}{ccc}
\hline Demographic Variables & Categories & Number (Percentage) \\
\hline \multirow{2}{*}{ Gender } & Male & $189(47.0 \%)$ \\
& Female & $213(53.0 \%)$ \\
\hline \multirow{2}{*}{ Age } & $18-25$ years & $101(25.1 \%)$ \\
& $26-40$ years & $215(53.5 \%)$ \\
& $41-55$ years & $70(17.4 \%)$ \\
Marital status & 56 years or more & $16(4.0 \%)$ \\
\hline \multirow{2}{*}{ Nationality } & Single or never married & $124(30.8 \%)$ \\
& Married & $253(62.9 \%)$ \\
& Separated & $17(4.2 \%)$ \\
& Divorced & $4(4.0 \%)$ \\
Highest educational level & Widowed & $4(4.0 \%)$ \\
& Saudi & $306(76.1 \%)$ \\
& Non-Saudi & $96(23.9 \%)$ \\
\hline \multirow{2}{*}{ Household monthly income * } & Primary school or lower & $31(7.7 \%)$ \\
& College or university & $116(28.9 \%)$ \\
\hline * Note: 1 USD & Less than 5000 SAR & $189(63.4 \%)$ \\
\hline
\end{tabular}

* Note: 1 USD = 3.75 SAR (Saudi Arabian Riyal).

A cross-sectional survey was performed using an online platform QuestionPro between January 2021 and March 2021. This method is preferred for its quick, economical, and eco-friendly manner of data gathering [54]. The snowball sampling method was used to share the survey link through emails and social media. Further, the participants were asked to share the link to other households in the study area [55]. The participation reached 402 at the end of March 2021. Based on the principle of Cochran's formula, the 1.28 million total residents of the area can be represented by a 0.05 percentage [56]. The snowball sampling method ensured that the study was conducted anonymously and with a high response rate [14]. The method also effectively reached the study participants by overcoming the difficulty of distributing the questionnaires to Saudi public because of cultural privacy issues [14]. However, there is a possible limitation related to the survey method, such as subjective and biased points of view from the study participants. Colleagues reviewed the questionnaire, after which it was pre-tested in a pilot survey to minimize this potential risk.

The collected data were analyzed using descriptive statistics (frequency distribution and percentages. Similarly, Pearson's Chi-square test was used to determine whether there is a statistically significant difference between respondents' awareness of and opinions on $\mathrm{CE}$ and their demographic characteristics such as age, gender, educational level, and income. The Chi-square test is suitable for analyzing the association between two or more independent categorical variables, as utilized in previous studies [57].

\section{Results and Discussion}

\subsection{Public Awareness and Perception of CE}

The perception of the public, as important stakeholders, towards $\mathrm{CE}$, is important towards CE transition in Saudi Arabia. This survey analyzed the public insight about "CE" along with "environmental protection". The findings revealed that $11 \%$ of the respondents stated that they had a great understanding of CE, while $51 \%$ were familiar with the concept but did not know what it means, and $38 \%$ had no idea what it is. On the other hand, only 
$9 \%$ were highly aware of environmental protection, while $65 \%$ were familiar with it, and $26 \%$ said they did not have any idea.

Since the literature indicates that the level of awareness of CE increased with the respondents' level of education, the present study explored and found a statistically significant difference $\left(X^{2}=42.655, p\right.$-value $\left.=0.001\right)$ in CE awareness according to respondents' highest educational level (Figure 2). Respondents with college/university education $(65.5 \%)$ have a significantly greater understanding of CE compared with those with secondary/intermediate school education (39.7\%) and those with primary education or less $(19.4 \%)$, which are in line with the previous literature [9]. In a study of five major towns and 69 villages in southern Jordan, awareness about environmental issues such as air and noise pollution, water efficiency, solid waste management, and desertification increases with increasing education, and higher among female than male survey respondents [45].

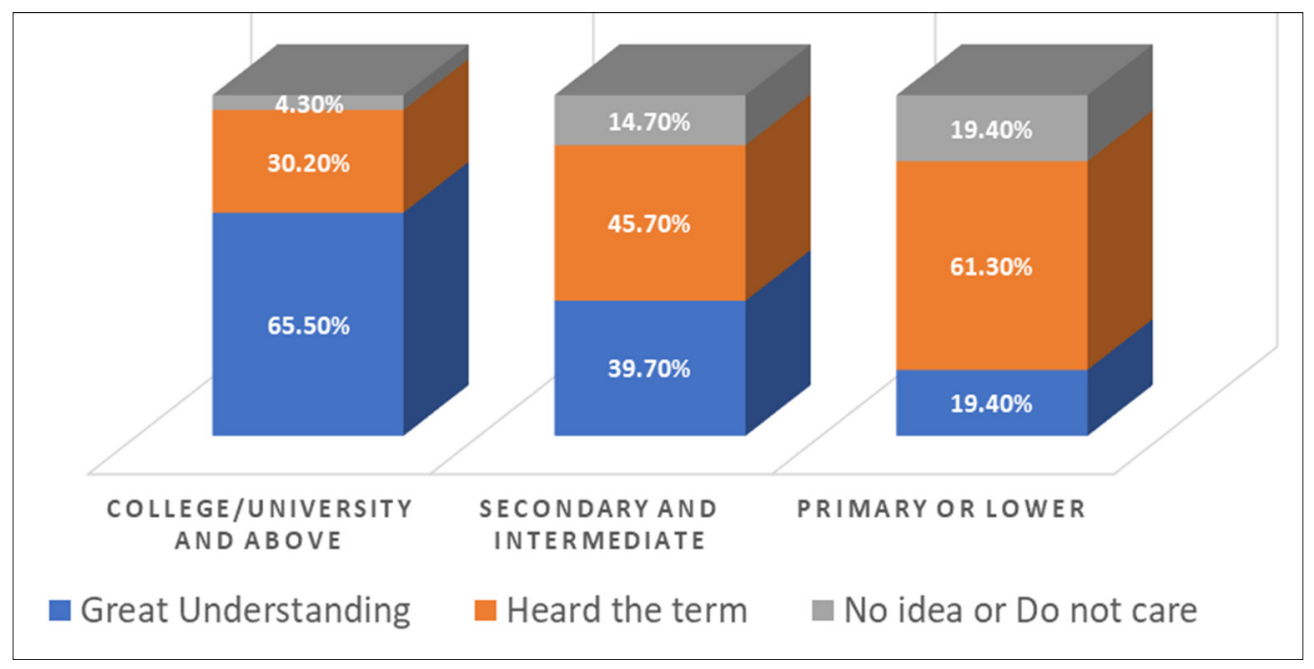

Figure 2. Understanding of CE according to respondents' education level $\left(X^{2}=42.655\right.$, $p$-value $=0.001)$.

In the open-ended questions section, respondents who said they understood CE extremely well were asked to provide some information about their knowledge regarding the subject. Most of them maintained that CE was equivalent to trash sorting or recycling, indicating a narrow understanding of the concept. The purpose of CE in Saudi Arabia is not only limited to waste disposal, but it also involves alteration in the allocation and industrial structure, urban infrastructure, distribution of social welfare, and environmental protection. In contrast, words such as eco-city and environmental protection are better understood by the respondents. Since any governmental strategy cannot be entirely successful without the involvement and support of its people, it is crucial to pay attention to motivating the public and promoting the culture of CE. A recent study on stakeholder perceptions of CE transition in the European Union reported that administrators, researchers, and economists all agree that $\mathrm{CE}$ implementation is costly for firms and consumers and that the government intervention can play a leading role in propagating a positive and viable image of the $\mathrm{CE}$ model, especially at the initial stage [21].

\subsection{Environmental Consciousness When Buying Goods}

Green consumption refers to the engagement and cooperation of the public in conserving resources and protecting the environment [35]. Thus, it entails the direct participation of the public to secure the environment and conserve its resources. In answering the question: "would you consciously purchase environmentally friendly (green) goods", around $62 \%$ of the participants of this study replied "yes", and 38\% answered "no".

When conducted among the various industrial sectors worldwide, a similar survey revealed that less than $50 \%$ of respondents considered purchasing green products currently, 
and on average, $33 \%$ of respondents chose the opposite [58]. In the open-ended sections of the present study, almost all the respondents showed signs of suspicion regarding the green claims on product labels. While some respondents assumed these were fake environmentally friendly products, others claimed that this was probably a marketing strategy. In another study, participants argued that the solution to plastic waste and environmental disaster was initiating pseudo-individualized green products by many corporations [59]. Furthermore, studies have indicated that the price sensitivity of green products undermined the environmental impact on the green consumption objective $[35,60,61]$. Therefore, by recognizing, understanding, and purchasing environmentally friendly labeled goods, a country's population can further encourage such products.

Evidence from Europe, the USA, Japan, and China indicates that CE helps in optimizing natural resource exploitation, rising operation efficacy, and transitioning from open to closed cycles of energy and materials, achieving few wasteful industrial processes by adopting the "cradle to cradle" perspective rooted in CE, and the 3R strategy that allows municipalities and companies to save cost in managing waste [4].

\subsection{Attitude towards Sorting and Recycling of Trash}

The most apparent ill-effect of uncontrolled consumption is the generation of excessive waste. The country's per capita waste generation is more than $1.5 \mathrm{~kg} /$ day. The country adopts various techniques for trash disposal, including the current practices of stockpiling non-segregated waste from residential quarters and disposing them on open deserted landfills or landfills. At this rate, the disposal sites will reach their capacity in the next five to ten years [12].

Therefore, the present study surveyed public opinion on trash sorting and their daily trash disposal methods. The survey result in Table 2 revealed that 217 respondents (54\%) have a positive attitude towards trash sorting. In the open-ended questions, some of them even stated that trash sorting was "extremely necessary". On the other hand, while 105 respondents (26\%) felt uncomfortable sorting trash, some commented that they appreciated the concept, but the process seemed highly inconvenient and tedious. Further, $20 \%$ of the respondents reported that they lack knowledge or instructions on this topic. As such, improved user awareness is a crucial strategy for the successful implementation of CE practices. According to Khan and Haleem [26], out of the 15 CE practices they identified and evaluated consumer awareness as the most effective practice necessary for transforming the linear economic model to CE.

Implementing the 3R strategy (reduce, recycle and reuse) to influence public behavior has recorded some success in a residential estate in the Eastern Province of Saudi Arabia that led to $46.7 \%$ garbage reduction from 5625 tons to 3000 tons annually [62]. Another study conducted in Dammam city, Saudi Arabia, revealed that $57.1 \%$ and $55.1 \%$ of 450 study respondents reported having a positive attitude regarding trash sorting and recycling, respectively [63]. A study in the United Kingdom also showed a positive public response towards trash segregation and its conversion into energy through incineration [64]. However, some residents expressed the process of segregation as tedious, time-consuming, and one-fourth of them admitted that they did not have enough instructions on the procedure. In an experimental study on residents' garbage sorting behaviors in Thailand, Leeabai et al. [65] reported that while $86 \%$ of participants sort their household waste, $72 \%$ considered it inconvenient or a waste of time. They concluded that raising public awareness can lead to more efficiency in collecting segregated wastes.

The use of efficient services might have a larger impact on the overall resource usage, than the use of energy or materials. The overall quantity of products produced can be reduced by improving the intensity of use through sharing and renting as alternate approaches instead of the traditional consumption pattern of ownership. This might also help to decompress the environmental pressure from economic growth. Unfortunately, people are not inclined towards renting or sharing any products as they are used to a high-consuming lifestyle and would rather opt to buy a new product for themselves and 
their children. An overall 78.7\% of the respondents replied "yes" to the question: "would you rather buy a new product or rent/share it"?

Table 2. Opinion about trash sorting and recycling of used products and packages.

\begin{tabular}{|c|c|c|c|c|}
\hline \multirow{2}{*}{$\begin{array}{l}\text { What are Your Views or Opinion } \\
\text { about Trash Segregation }\end{array}$} & \multicolumn{3}{|c|}{ How Do You Discard Used Commodities and the Packaging? } & \multirow[b]{2}{*}{ Total } \\
\hline & $\begin{array}{c}\text { Reuse Packages More } \\
\text { Than Once }\end{array}$ & Sell Used Packages & Throw It in the Trash & \\
\hline Positive attitude towards trash sorting & $60(27.6 \%)$ & $117(53.9 \%)$ & $40(18.4 \%)$ & $217(100.0 \%)$ \\
\hline Uncomfortable towards trash sorting & $31(29.5 \%)$ & $47(44.8 \%)$ & $27(25.7 \%)$ & $105(100.0 \%)$ \\
\hline Lack knowledge on this topic & $11(13.8 \%)$ & $57(71.3 \%)$ & $12(15.0 \%)$ & $80(100.0 \%)$ \\
\hline \multicolumn{5}{|c|}{ Chi-Square $=14.315(p$-value $=0.006)$} \\
\hline
\end{tabular}

In the open-ended questions sections, most respondents felt economically stable enough to purchase a new item instead of renting or sharing. However, a significant fraction also reported that sharing items of everyday use makes them feel threatened regarding their health, particularly at the peak of the COVID-19 pandemic. In contrast, individuals with low monthly household income responded "no" to the question: "would you rather buy a new product than rent/share it"? However, more research is on this topic to assess the factors that influence sharing items compared to buying brand new ones.

For governments such as Saudi Arabia's that aim to achieve long-term sustainability, incorporating production principles into everyday routines and sustainable consumption is a policy-related challenge. Thus, it is highly important to know more details regarding public environmental protection and resource conservation behavior. Creating awareness and helping the people understand the importance of SD will help the government implement a new policy and the most cost-effective mass education initiatives.

A similar study by Ghisellini et al. [7] found that consumers are practically more concerned about recycling than reuse, which as a main pillar of CE could reduce climate change impacts and improve local livelihoods [66]. Therefore, recycling activities should be promoted more locally than universally to avoid losing key industrial resources [7].

\subsection{Purchasing Environmentally Friendly (Green) Goods}

An increasing number of people have shown interest in consciously purchasing environmentally friendly goods. Consumers can now choose from a wide range of these goods including, energy-saving electronics, household cleaning products, and even laundry detergents. Findings from this study revealed that a significant proportion of respondents preferred to purchase safe items for their well-being, such as green foods, electronics, and detergents. In contrast, a lesser percentage of people prefer products that are beneficial for the global or local climates (Table 3). While over half of the participants said, they would like to purchase organic food, water, and energy-saving goods, about three-quarters of them would purchase eco-friendly laundry detergents and baby products, and energysaving electronics.

Table 3. Types of environmentally friendly goods respondents will prefer to buy.

\begin{tabular}{ccc}
\hline Preferred Choices of Commodities (Multiple Choices) & Number & Percent \\
\hline Items with biodegradable packaging & 176 & $43.7 \%$ \\
Products labeled Eco-friendly & 201 & $50.0 \%$ \\
Organic foods over non-organic food & 252 & $62.2 \%$ \\
Water and energy-saving appliances & 268 & $65.4 \%$ \\
Non-CFCs fridge, freezers, and air conditioners & 299 & $74.3 \%$ \\
Low-noise and low-radiation electronics & 309 & $76.8 \%$ \\
Eco-friendly laundry detergents and baby products & 319 & $79.3 \%$ \\
\hline
\end{tabular}


There is a statistically significant difference between all demographic variables and purchasing environmentally friendly (green) goods $(p$-value $<0.01)$. The results in Table 4 favor respondents that are Saudis, male, married, 26-40 olds, and with college/university education and monthly household income of more than 10,000 SAR. Guo et al. [8] conducted a similar study in Urumqi city (China) and found that over $50 \%$ of survey respondents gave precedence to the environment over the use of plastic shopping bags. However, Urumqi city is still in an early development stage regarding environmental pollution, and the philosophy of "pollution first and treatment later" is popular. Wijkman and Skanberg [67] estimate that full transformation of a country's economy to a CE can reduce greenhouse gas emissions by $70 \%$ and grow the workforce by $4 \%$. Designing products for circularity (environmentally friendly) is a key practice that is central to $\mathrm{CE}$ as it lengthens product life cycle and significantly reduces waste [21].

Table 4. Would you consciously purchase environmentally friendly (green) goods?

\begin{tabular}{|c|c|c|c|c|}
\hline \multicolumn{2}{|c|}{ Variable } & \multirow{3}{*}{$\begin{array}{c}\text { Yes } \\
100.0 \% \\
28.2 \%\end{array}$} & \multirow{3}{*}{$\begin{array}{c}\text { No } \\
0.0 \% \\
71.8 \%\end{array}$} & \multirow{3}{*}{$\begin{array}{c}\text { Chi-Square } \\
219.180^{* *}(\mathrm{df}=1)\end{array}$} \\
\hline & Male & & & \\
\hline Gender: & Female & & & \\
\hline \multirow{4}{*}{ Age: } & 18-25 years & $0.0 \%$ & $100.0 \%$ & \multirow{4}{*}{$205.250 * *(\mathrm{df}=3)$} \\
\hline & $26-40$ years & $100.0 \%$ & $0.0 \%$ & \\
\hline & 41-55 years & $48.6 \%$ & $51.4 \%$ & \\
\hline & 56 years or more & $0.0 \%$ & $100.0 \%$ & \\
\hline \multirow{5}{*}{ Marital status: } & Single & $7.3 \%$ & $92.70 \%$ & \multirow{5}{*}{$314.282 * *(\mathrm{df}=4)$} \\
\hline & Married & $94.9 \%$ & $5.1 \%$ & \\
\hline & Separated & $0.0 \%$ & $100.0 \%$ & \\
\hline & Divorced & $0.0 \%$ & $100.0 \%$ & \\
\hline & Widowed & $0.0 \%$ & $100.0 \%$ & \\
\hline \multirow{2}{*}{ Nationality: } & Saudi & $18.6 \%$ & $81.4 \%$ & \multirow{2}{*}{$327.827^{* *}(\mathrm{df}=1)$} \\
\hline & Non-Saudi & $0.0 \%$ & $100.0 \%$ & \\
\hline \multirow{3}{*}{ Highest educational level: } & Primary school or lower & $40.0 \%$ & $60.0 \%$ & \multirow{3}{*}{$142.395^{* *}(\mathrm{df}=2)$} \\
\hline & Intermediate or secondary & $40.0 \%$ & $60.0 \%$ & \\
\hline & College or university & $100.0 \%$ & $0.0 \%$ & \\
\hline \multirow{3}{*}{ Household monthly income } & Less than 5000 SAR & $0.0 \%$ & $100.0 \%$ & \multirow{3}{*}{$208.068^{* *}(\mathrm{df}=2)$} \\
\hline & 5000-10,000 SAR & $0.0 \%$ & $100.0 \%$ & \\
\hline & More than 10,000 SAR & $81.6 \%$ & $18.4 \%$ & \\
\hline
\end{tabular}

** Significant at $p=0.01$.

\subsection{Everyday Conservation Behavior of Respondents}

This study also assessed respondents' conservation and post-purchase behaviors. A significant number of residents paid more attention to maintaining machines and electronics and the conservation of electricity and water in their everyday lives than reusing packages and containers of purchased commodities (Table 5). Chi-square analysis indicates that this behavior is significantly associated $(p$-value $=0.001)$ with the difference in age of the respondents. The findings revealed that the middle age (41-55 years) respondents $(88.6 \%)$ and elderly populations above 56 years $(68.6 \%)$ were significantly more likely to maintain and repair their machines and electronics compared to those aged 24-40 years $(20.9 \%)$ and those less than 25 years $(42.6 \%)$.

Quite impressively, respondents less than 25 years old $(92.1 \%)$ are more inclined towards conserving water and electricity, followed by those aged more than 56 years $(81.2 \%)$ and those aged $41-55$ years $(74.3 \%)$. There is also a statistically significant difference between age group and reuse of packaging commodities (Chi-square $=30.777$, $p$-value $=0.000$ ) in favor of under 25 age group that had the highest percent of selling used packaging commodities with $38.6 \%$. 
Table 5. Conservation behavior according to respondents' age.

\begin{tabular}{|c|c|c|c|c|c|c|}
\hline \multirow[t]{2}{*}{ Age Group } & \multicolumn{2}{|c|}{$\begin{array}{l}\text { Do You Maintain and Repair Your } \\
\text { Machines and Electronics to Boost } \\
\text { Their Shelf-Life? }\end{array}$} & \multicolumn{2}{|c|}{$\begin{array}{c}\text { Do You Try to Save Electricity and } \\
\text { Water in Daily Use? }\end{array}$} & \multicolumn{2}{|c|}{$\begin{array}{c}\text { Do You Reuse More Than Once } \\
\text { Packages of Purchased Commodities? }\end{array}$} \\
\hline & Yes & No & Yes & No & Yes & No \\
\hline $18-25$ years $(n=101)$ & $43(42.6 \%)$ & $58(57.4 \%)$ & $93(92.1 \%)$ & $8(7.9 \%)$ & $39(38.6 \%)$ & $62(61.4 \%)$ \\
\hline $26-40$ years $(n=215)$ & $45(20.9 \%)$ & $170(79.1 \%)$ & $108(50.2 \%)$ & $107(49.8 \%)$ & $28(13.0 \%)$ & $187(87.0 \%)$ \\
\hline $41-55$ years $(n=70)$ & $62(88.6 \%)$ & $8(11.4 \%)$ & $52(74.3 \%)$ & $18(25.7 \%)$ & $10(14.3 \%)$ & $60(85.7 \%)$ \\
\hline \multirow[t]{2}{*}{$56 \leq$ years $(n=16)$} & $11(68.8 \%)$ & $5(31.3 \%)$ & $13(81.2 \%)$ & $3(18.8 \%)$ & $2(12.5 \%)$ & $14(87.5 \%)$ \\
\hline & \multicolumn{2}{|c|}{$\chi^{2}=107.132(p$-value $=0.001)$} & \multicolumn{2}{|c|}{$\chi^{2}=58.368(p$-value $=0.001)$} & \multicolumn{2}{|c|}{$\chi^{2}=30.777(p$-value $=0.001)$} \\
\hline
\end{tabular}

Although $97 \%$ of the Saudi Arabian population has safe drinking water, the country still has extremely limited water resources [68]. Therefore, water conservation is extremely important here. In addition, the country currently experiences a serious over-consumption issue and lacks reliable renewable water resources [69]. Therefore, water is soon becoming a rare asset in the country [70]. Therefore, the government should design programs to create more awareness on this topic among the country's residents to combat this challenge.

For comparison with these results, a similar survey conducted in China revealed that respondents assign the highest importance to CE practices that are directly related to energy conservation with economic co-benefits [42]. They gave secondary importance to practices related to their health and safety, such as air quality, radiation, and pollution. Another study found that DMA inhabitants have fewer tendencies to reuse treated wastewater for household functions [40]. In Urumqi city (China), Guo et al. [8] found that over $94 \%$ of their study participants reused water, at least $80 \%$ have energy-saving lamps at home, but fewer than $54 \%$ reused shopping bags.

Spearman's correlation analysis was also performed to test the relationship between respondents' preference for trash segregation and their level of CE awareness. The result shows a positive moderate significant relationship between user likelihood for trash segregation and awareness of the term $C E(r=0.450, p$-value $<0.01)$, indicating that the higher the level of $\mathrm{CE}$ awareness, the more positive attitude towards trash segregation. The literature indicates that $\mathrm{R}$ practices, including reducing, reusing, recycling, recovering, redesigning, and remanufacturing products, offer better performance to supply chains [26]. However, the reuse and remanufacture practices are labor-intensive rather than resource-intensive in the linear model of production and consumption [7].

Van Langen et al. [21] reviewed and summarized the barriers to CE transition, which are resistant to change, less awareness, unfavorable prices of circular commodities, lack of policies and regulations, and existing linear design of commodities. The authors suggested that to foster transition to $\mathrm{CE}$, there is the need to promote innovative, comprehensive, and long-term national CE policies. They also recommended developing appropriate circular infrastructure to promote waste prevention and easy transportation, storage, and marketing of circular commodities. Lastly, providing incentives such as low taxes and subsidies to materials recycling, promoting research in circular technology and product designs, increasing public awareness, and involving stakeholders in decision-making are critical to CE transition.

\section{Conclusions}

The majority of the participants of this study have an impaired understanding of the term CE, positive attitude towards trash segregation based on whether it can be exchanged, reused, or sold. About one-quarter of the respondents stated that the segregation of trash was somewhat inconvenient. Additionally, about three out of five of them showed an inclination towards purchasing environmentally friendly goods. Most participants prioritize environmental factors tied to reducing energy and water consumption because of financial savings. They also perceive environmental factors from their safety and health perspectives instead of consideration for local and international environments. These 
results have significant implications for both the implementation and the development of $\mathrm{CE}$ plans and campaigns. At the same time, the local authorities and the government are setting up new goals in the promotion of $\mathrm{CE}$; the public lacks adequate information to guide them on how they should actively participate. Therefore, currently, these efforts translate into economic consumption behaviors instead of conscious conservative behaviors.

Moreover, there is an urgent need to create awareness and provide adequate information to the consumers about reliable, environmentally friendly products and services. The findings can create awareness among Saudi residents and make them realize their responsibilities towards conserving depleting resources. It has also laid the basis for future studies on this topic.

Therefore, schemes for recycling and sorting must be designed considering the consumers' convenience. The information gathered also supports the fact that although waste recycling is extremely important according to the political agenda in Saudi Arabia, methods to bring recycling schemes into implementation are usually lacking. Many other barriers, such as financial constraints, and planning-related issues, delay and complicate the creation of national-level recycling systems and campaigns. People who are financially secure and well educated are more drawn towards new product ownership. Thus, normalizing the sharing of goods and other such behaviors that can result in sustainable consumption is an important change towards the SD of Saudi Arabia.

Concerning demographic characteristics, the residents' level of awareness regarding $\mathrm{CE}$ is positively correlated with their educational background. In contrast, their resource conservative and pro-environmental behavior was positively correlated with their age. Therefore, it is necessary to promote conservative behaviors among the younger population to create awareness about $\mathrm{CE}$. Although $\mathrm{CE}$ transition has begun in the country and its implementation has great potential, several gaps should be filled to make it succeed. One of such gaps is improving public awareness to embrace CE strategies.

Even though this study has provided valuable data to policymakers, certain limitations to the approach should also be highlighted. First, to understand the general population's participation in $\mathrm{CE}$ and its idea, as presented in the questionnaire, focused mainly on the 3Rs of the usage behavior. As a result, this study did not consider the repercussions of using energy resources for recycling, waste generated through recycling process, and the CE system boundaries that could undermine sustainability. As such, future studies are required to address this limitation. Second, this study's sample size was small, limiting the generalization of the study findings to the country's entire population.

Future research on this topic should investigate the factors that could influence proenvironmental behavior among residents. There is also a need to expand the scope of this research beyond one city. An extensive study conducted at a national level can offer a better picture about public understanding of CE in Saudi Arabia. Subsequent research to study the organizational and socioeconomic factors that can overcome the hindrances to the successful implementation of a CE plan is also essential. The outcomes of such a study can be used to create better CE marketing strategies.

Author Contributions: Conceptualization, A.I.A.; methodology, I.R.A. and A.I.A.; formal analysis, A.I.A. and I.R.A.; investigation, I.R.A. and A.I.A.; resources, A.I.A. and I.R.A.; data curation, A.I.A.; writing—original draft preparation, A.I.A.; writing—review and editing, I.R.A.; visualization, I.R.A.; funding acquisition, A.I.A. All authors have read and agreed to the published version of the manuscript.

Funding: This research received no external funding.

Institutional Review Board Statement: Not applicable.

Informed Consent Statement: Informed consent was obtained from all subjects involved in the study.

Acknowledgments: The authors greatly acknowledge the support of Imam Abdulrahman Bin Faisal University, Dammam, Saudi Arabia.

Conflicts of Interest: The authors declare no conflict of interest. 


\section{References}

1. Geissdoerfer, M.; Savaget, P.; Bocken, N.M.; Hultink, E.J. The Circular Economy-A new sustainability paradigm? J. Clean. Prod. 2017, 143, 757-768. [CrossRef]

2. Rogers, H.A.; Deutz, P.; Ramos, T.B. Repairing the circular economy: Public perception and participant profile of the repair economy in Hull, UK. Resour. Conserv. Recycl. 2021, 168, 105447. [CrossRef]

3. Dagilienè, L.; Varaniūtè, V.; Bruneckienè, J. Local governments' perspective on implementing the circular economy: A framework for future solutions. J. Clean. Prod. 2021, 310, 127340. [CrossRef]

4. Leal Filho, W.; Abubakar, I.R.; Kotter, R.; Grindsted, T.S.; Balogun, A.L.; Salvia, A.L.; Aina, Y.A.; Wolf, F. Framing Electric Mobility for Urban Sustainability in a Circular Economy Context: An Overview of the Literature. Sustainability 2021, 13, 7786. [CrossRef]

5. German Federal Environmental Agency. 9 Principles for a Circular Economy; UBA: Dessau, Germany, 2020; Available online: https://www.umweltbundesamt.de/sites/default/files/medien/1410/publikationen/2020_10_23_leitlinie_ kreislaufwirtschaft_englisch_bf.pdf (accessed on 21 May 2021).

6. Abubakar, I.R.; Bununu, Y.A. Low carbon city: Strategies and case studies. In Sustainable Cities and Communities. Encyclopedia of Sustainability in Higher Education; Springer: Cham, Switzerland, 2020; pp. 366-376.

7. Ghisellini, P.; Cialani, C.; Ulgiati, S. A review on circular economy: The expected transition to a balanced interplay of environmental and economic systems. J. Clean. Prod. 2016, 114, 11-32. [CrossRef]

8. Guo, B.; Geng, Y.; Sterr, T.; Zhu, Q.; Liu, Y. Investigating public awareness on circular economy in western China: A case of Urumqi Midong. J. Clean. Prod. 2017, 142, 2177-2186. [CrossRef]

9. Guerra, B.C.; Leite, F. Circular economy in the construction industry: An overview of United States stakeholders' awareness, major challenges, and enablers. Resour. Conserv. Recycl. 2021, 170, 105617. [CrossRef]

10. Oscar, F.; Benson, D.; Monciardini, D. All around the world: Assessing optimality in comparative circular economy policy packages. J. Clean. Prod. 2021, 286, 125493.

11. Ibrahim, A.J.; Shirazi, N.S. Energy-Water- Environment Nexus and the Transition towards a Circular Economy: The Case of Qatar. Circ. Econ. Sustain. 2021, 1-16. [CrossRef]

12. Abubakar, I.R.; Dano, U.L. Sustainable urban planning strategies for mitigating climate change in Saudi Arabia. Environ. Dev. Sustain. 2020, 22, 5129-5152. [CrossRef]

13. SIRC (Saudi Investment Recycling Company). Leading the Circular Economy in Saudi Arabia. 2021. Available online: https: / / sirc.sa (accessed on 2 August 2021).

14. Alqahtany, A.M.; Abubakar, I.R. Public perception and attitudes to disaster risks in a coastal metropolis of Saudi Arabia. Int. J. Disaster Risk Reduct. 2020, 44, 101422. [CrossRef]

15. Arab News. SEC's Progress toward Sustainability on Track. Arab News, 9 September 2020. Available online: https://www. arabnews.com/node/1732206/corporate-news (accessed on 13 March 2021).

16. Malik, K.; Rahman, S.M.; Khondaker, A.N.; Abubakar, I.R.; Aina, Y.A.; Hasan, M.A. Renewable energy utilization to promote sustainability in GCC countries: Policies, drivers, and barriers. Environ. Sci. Pollut. Res. 2019, 26, 20798-20814. [CrossRef]

17. Government of Saudi Arabia. National Transformation Program. Vision 2030. Available online: https:/ /www.vision2030.gov.sa/ v2030/vrps/ntp/ (accessed on 18 March 2021).

18. Alshammari, H. What Saudi Vision 2030 Reform Plan Has Achieved at the Five-Year Mark. 2021. Available online: https: / / www.arabnews.com/node/1849981/saudi-arabia (accessed on 22 May 2021).

19. Gamal, R. Saudi Arabia Plans to Launch Carbon Trading Scheme. 2019. Available online: https://www.reuters.com/article/ussaudi-investments-energy-idUSKBN1X91M1 (accessed on 29 March 2021).

20. Abubakar, I.R.; Aina, Y.A.; Alshuwaikhat, H.M. Sustainable development at Saudi Arabian universities: An overview of institutional frameworks. Sustainability 2020, 12, 8008. [CrossRef]

21. van Langen, S.K.; Vassillo, C.; Ghisellini, P.; Restaino, D.; Passaro, R.; Ulgiati, S. Promoting circular economy transition: A study about perceptions and awareness by different stakeholders' groups. J. Clean. Prod. 2021, 316, 128166. [CrossRef]

22. Kuah, A.T.; Wang, P. Circular economy and consumer acceptance: An exploratory study in East and Southeast Asia. J. Clean. Prod. 2020, 247, 119097. [CrossRef]

23. Liu, Q.; Li, H.-M.; Zuo, X.-1.; Zhang, F.-F.; Wang, L. A survey and analysis on public awareness and performance for promoting circular economy in China: A case study from Tianjin. J. Clean. Prod. 2009, 17, 265-270. [CrossRef]

24. Marios, T.; Giannis, I.; Dimitra, L. Investigation of Factors Affecting Consumers' Awareness on Circular Economy: Preliminary Evidence from Greece. J. Reg. Socio-Econ. Issues 2018, 8, 47-57.

25. Smol, M.; Avdiushchenko, A.; Kulczycka, J.; Nowaczek, A. Public awareness of circular economy in southern Poland: Case of the Malopolska region. J. Clean. Prod. 2018, 197, 1035-1045. [CrossRef]

26. Khan, S.; Haleem, A. Investigation of circular economy practices in the context of emerging economies: A CoCoSo approach. Int. J. Sustain. Eng. 2021, 14, 1-11. [CrossRef]

27. United Nations. Transforming Our World: The 2030 Agenda for Sustainable Development; United Nations: New York, NY, USA, 2015; Available online: https:/ /sdgs.un.org/2030agenda (accessed on 2 August 2021).

28. Chowdhury, M.M.I.; Rahman, S.M.; Abubakar, I.R.; Aina, Y.A.; Hasan, M.A.; Khondaker, A.N. A review of policies and initiatives for climate change mitigation and environmental sustainability in Bangladesh. Environ. Dev. Sustain. 2021, 23, 1133-1161. [CrossRef] 
29. Ministry of Ecology and Environment. Task Force Report on Circular Economy. 2005. Available online: http:/ / english.mee.gov. cn/Events/Special_Topics/AGM_1/Pub05AGM/meetingdoc05/201605/t20160524_344884.shtml (accessed on 11 April 2021).

30. Akbar, N.; Abubakar, I.R.; Bouregh, A.S. Fostering Urban Sustainability through the Ecological Wisdom of Traditional Settlements. Sustainability 2020, 12, 33. [CrossRef]

31. Zafar, S. Solid Waste Management in Saudi Arabia. EcoMENA. 2020. Available online: https://www.ecomena.org/solid-wastemanagement-in-saudi-arabia/ (accessed on 21 March 2021).

32. Witek, L.; Kuźniar, W. Green purchase behavior: The effectiveness of sociodemographic variables for explaining green purchases in emerging market. Sustainability 2021, 13, 209. [CrossRef]

33. Zhuang, W.; Luo, X.; Riaz, M.U. On the Factors Influencing Green Purchase Intention: A Meta-Analysis Approach. Front. Psychol. 2021, 12, 1074. [CrossRef]

34. White, K.; Habib, R.; Hardisty, D.J. How to SHIFT Consumer Behaviors to be More Sustainable: A Literature Review and Guiding Framework. J. Mark. 2019, 83, 22-49. [CrossRef]

35. Yue, B.; Sheng, G.; She, S.; Xu, J. Impact of consumer environmental responsibility on green consumption behavior in China: The role of environmental concern and price sensitivity. Sustainability 2020, 12, 2074. [CrossRef]

36. Boz, Z.; Korhonen, V.; Sand, C.K. Consumer considerations for the implementation of sustainable packaging: A review. Sustainability 2020, 12, 2192. [CrossRef]

37. OECD. Household Behaviour and the Environment-Reviewing the Evidence. 2008. Available online: https://www.oecd.org/ greengrowth/consumption-innovation/42183878.pdf (accessed on 14 February 2021).

38. World Population Review. Population of Cities in Saudi Arabia. 2021. Available online: https://worldpopulationreview.com/ countries/cities/saudi-arabia (accessed on 24 August 2021).

39. IMF (International Monetary Fund). Saudi Arabia: 2019 Article IV Consultation-Press Release and Staff Report; IMF: Washington, DC, USA, 2019; p. 290.

40. Mu'azu, N.D.; Abubakar, I.R.; Blaisi, N.I. Public acceptability of treated wastewater reuse in Saudi Arabia: Implications for water management policy. Sci. Total Environ. 2020, 721, 137659. [CrossRef]

41. Kane, F. G20 Backs Saudi Arabia's Circular Carbon Economy Strategy. 2020. Available online: https://www.arabnews.com/ node/1741541/business-economy (accessed on 9 February 2021).

42. Hao, Y.; Wang, Y.; Wu, Q.; Sun, S.; Wang, W.; Cui, M. What affects residents' participation in the circular economy for sustainable development? Evidence from China. Sustain. Dev. 2020, 28, 1251-1268. [CrossRef]

43. Testa, F.; Iovino, R.; Iraldo, F. The circular economy and consumer behaviour: The mediating role of information seeking in buying circular packaging. Bus. Strategy Environ. 2020, 29, 3435-3448. [CrossRef]

44. Atlason, R.S.; Giacalone, D.; Parajuly, K. Product design in the circular economy: Users' perception of end-of-life scenarios for electrical and electronic appliances. J. Clean. Prod. 2017, 168, 1059-1069. [CrossRef]

45. Ziadat, A.H. Major Factors contributing to environmental awareness among people in a third world country/Jordan. Environ. Dev. Sustain. 2010, 12, 135-145. [CrossRef]

46. Lee, J.; Cho, M. New insights into socially responsible consumers: The role of personal values. Int. J. Consum. Stud. 2019, 43, 123-133. [CrossRef]

47. Siddiqui, M. Principles and Guidelines for the Development of Eco-Industrial Parks: A Case Study of Jubail, Saudi Arabia. In Proceedings of the 12th International Conference of Greening of Industry Network, Hong Kong, China, 7-10 November 2004; Available online: https:/ / gin.confex.com/gin/2004/techprogram/P1212.HTM (accessed on 21 February 2021).

48. Macrotrends. Ad-Dammam, Saudi Arabia Metro Area Population 1950-2021. 2021. Available online: https://www.macrotrends. net/cities/22416/ad-dammam/population (accessed on 3 March 2021).

49. Alkhamis, A.; Miraj, S.A. Access to Health Care in Saudi Arabia: Development in the Context of Vision 2030. In Handbook of Healthcare in the Arab World; Springer: Cham, Switzerland, 2020; pp. 1-34.

50. Government of Saudi Arabia. Saudi Vision 2030; Government of Saudi Arabia: Riyadh, Saudi Arabia, 2016; pp. 1-85. Available online: https:/ / www.vision2030.gov.sa/media/rc0b5oy1/saudi_vision203.pdf (accessed on 3 March 2021).

51. Water World. Saudi Arabia Launches Program for a Drastic Reduction in Water Use. 2021. Available online: https: / / www.waterworld.com/international/potable-water/article/16202937/saudi-arabia-launches-program-for-a-drasticreduction-in-water-use (accessed on 29 April 2021).

52. UN-Habitat. Saudi Cities Report 2018; Ministry of Municipal and Rural Affairs: Riyadh, Saudi Arabia, 2019. Available online: https:/ / unhabitat.org/sites/default/ files / documents/2020-05/saudi_cities_report_-_excutive_summary_english.pdf (accessed on 17 January 2021).

53. Saudi National Portal for Government Services (GOV.SA.). Sustainable Development. 2021. Available online: https://www.my. gov.sa/wps/portal/snp/content/SDGPortal (accessed on 2 March 2021).

54. Srivastav, A.K.; Sharma, N.; Samuel, A.J. Impact of Coronavirus disease-19 (COVID-19) lockdown on physical activity and energy expenditure among physiotherapy professionals and students using web-based open E-survey sent through WhatsApp, Facebook and Instagram messengers. Clin. Epidemiol. Glob. Health 2021, 9, 78-84. [CrossRef]

55. Parker, C.; Scott, S.; Geddes, A. Snowball Sampling; SAGE Publications Limited: New York, NY, USA, 2020.

56. Adam, A.M. Sample Size Determination in Survey Research. J. Sci. Res. Rep. 2020, 26, 90-97. [CrossRef] 
57. Abubakar, I.R. Understanding the socioeconomic and environmental indicators of household water treatment in Nigeria. Util. Policy 2021, 70, 101209. [CrossRef]

58. Masi, D.; Kumar, V.; Garza-Reyes, J.A.; Godsell, J. Towards a more circular economy: Exploring the awareness, practices, and barriers from a focal firm perspective. Prod. Plan. Control. 2018, 29, 539-550. [CrossRef]

59. Smith, O.; Brisman, A. Plastic Waste and the Environmental Crisis Industry. Crit. Criminol. 2021, 29, 289-309. [CrossRef] [PubMed]

60. Awan, U.; Khattak, A.; Rabbani, S.; Dhir, A. Buyer-Driven Knowledge Transfer Activities to Enhance Organizational Sustainability of Suppliers. Sustainability 2020, 12, 2993. [CrossRef]

61. Al-Saidi, M.; Das, P.; Saadaoui, I. Circular Economy in Basic Supply: Framing the Approach for the Water and Food Sectors of the Gulf Cooperation Council Countries. Sustain. Prod. Consum. 2021, 27, 1273-1285. [CrossRef]

62. Hadidi, L.A.; Ghaithan, A.; Mohammed, A.; Al-Ofi, K. Deploying municipal solid waste management 3R-WTE framework in Saudi Arabia: Challenges and future. Sustainability 2020, 12, 5711. [CrossRef]

63. Labib, O.; Manaf, L.; Sharaai, A.H.; Zaid, S.S.M. Moderating effects on residents' willingness in waste sorting to improve waste handling in Dammam city, Saudi Arabia. Recycling 2021, 6, 24. [CrossRef]

64. Gardiner, B. In Europe, a Backlash Is Growing Over Incinerating Garbage. Yale E360. 2021. Available online: https:/ / e360.yale. edu/features/in-europe-a-backlash-is-growing-over-incinerating-garbage (accessed on 29 April 2021).

65. Leeabai, N.; Areeprasert, C.; Khaobang, C.; Viriyapanitchakij, N.; Bussa, B.; Dilinazi, D.; Takahashi, F. The effects of color preference and noticeability of trash bins on waste collection performance and waste-sorting behaviors. Waste Manag. 2021, 121, 153-163. [CrossRef] [PubMed]

66. Hasan, M.A.; Abubakar, I.R.; Rahman, S.M.; Aina, Y.A.; Chowdhury, M.M.I.; Khondaker, A.N. The synergy between climate change policies and national development goals: Implications for sustainability. J. Clean. Prod. 2020, 249, 119369. [CrossRef]

67. Wijkman, A.; Skanberg, K. Circular Economy and Benefits from Society; Club of Rome: Winterthur, Switzerland, 2015.

68. Alexander, L. Water Crisis in Saudi Arabia. The Borgen Project. 2021. Available online: https://borgenproject.org/water-crisis-insaudi-arabia/\#:\%7E:text=While\%2097\%25\%20of\%20Saudis\%20have, meters\%20per\%20capita\%2C\%20per\%20year (accessed on 13 March 2021).

69. Abubakar, I.R.; Aina, Y.A. Achieving sustainable cities in Saudi Arabia: Juggling the competing urbanization challenges. In Population Growth and Rapid Urbanization in the Developing World; IGI Global: Hershey, PA, USA, 2016; pp. $42-63$.

70. Almulhim, A.I.; Aqil, M.; Ahmad, S.; Abdel-Magid, I.M. Sustainable water planning and management research in Saudi Arabia: A data-driven bibliometric analysis. Arab. J. Geosci. 2021, 14, 1-14. [CrossRef] 